\title{
Uyghur Turkic Women and Cultural Expectations: Moslem Society in Change
}

\author{
David Makofsky \\ Ethnic Minorities Studies Center Minorities University of China
}

\begin{abstract}
Profound cultural changes are transforming the Moslem world of Central Asia, partly as a response to dramatic events in the Middle East and partly to the great economic development in the region. These changes in the Moslem world especially affect the lives of women, since the cultural norms involving the protection of women are an important facet of Moslem life. The goal of this investigation is to show the importance of the ethnographic contribution to anthropological and sociological theory in investigating the new aspects of life in Central Asia. The first concept is the cultural identity of the Uyghur population of China. The second concept is that of Uyghur women, namely, the varied range of women from their role in a conservative, and patriarchal family structure to that of independent actors in a contemporary urban society. We understand that young Uyghur women face a more different set of choices than those of women in other Moslem cultures or in the rest of China. If they identify with their culture as Uyghur and Moslem, their culture restricts their opportunities as Chinese citizens. As students at Minorities University of China (MUC) in Beijing, the relative freedom of Beijing influences them a great deal. Education and employment are the vehicles for integration into the larger Chinese group. Institutions, such as schools of ethnic studies, and the college competitive exam (the gaokao), provide opportunities as well as obstacles for Uyghur women as part of the dynamic change in the Moslem world.
\end{abstract}

Keywords: Uyghurs, Moslem women, affirmative action in Chins, education

\section{Introduction and Theory}

The period since the fall of the Soviet Union (1989) has ushered in profound changes in the Muslim world of Central Asia and the Middle East. The break-up of the Soviet Union gave rise to a series of ethnic Muslim identified states. The USSR has offered major financial and political support to some governments in the Middle East. Ultimately, these changes affected Muslim culture and the lives of women. This investigation explored those changes.

An earlier paper (Makofsky 2013) explored the character of this change by focusing on the statistical evidence. Ethnographic evidence also illustrates the impact of a changing culture on the lives of Uyghur women in Beijing.

The Uyghurs are a Turkic people of North West China primarily living in the Uyghur Autonomous Region of Xinjiang, closely related to their Kazakh, Uzbek, and Turkmen neighbors in language, culture, and ethnicity.

David Makofsky, Ph.D., professor, Ethnic Minorities Studies Center of China, Peoples Republic of China; Visiting Scholar, Anthropology and History, Queens University of Belfast, United Kingdom; main research fields: Muslim Cultural Change, Uyghurs, Women, Artist, and Artisan. Email: dmakofsky2001@yahoo.com. 
They are a small group in terms of China's population of 1.3 billion, numbering 8.3 million. Although the region was formerly obscure, Xinjiang is a part of a wealthy and increasingly powerful modern China. The Uyghurs are a critical part of "Islamic China." Over the last few years, there has been considerable urban development in the region, but in general, most Uyghurs were raised in rural areas. Not many Uyghurs have been outside of Xinjiang province. One reason is that Uyghur, rather than Chinese, is the first language for the local population. In Xinjiang, Uyghur and Chinese speakers often live in separate worlds due to language difficulties and ethnic misunderstandings.

The utility of social science theory to the investigation of cultural change has been documented over the course of the past half-century. Two of the most important observations are: (1) the role of cultural identity and (2) the investigation of the ideal-typical continuum used in the investigation of women, ranging from a subservient role in a patriarchal family structure to that of an independent actor.

These investigation documents change in China, in Moslem culture, and in the lives of women by looking at young Uyghur women enrolled in the Minorities University of China (MUC). The study took place in Beijing and Kashgar, a large population center of Uyghurs in Western China, over a period of months during 2011 and 2012. The three women discussed are examples of theoretical social science constructs in the lives of people.

\subsection{Cultural Identity}

The Uyghurs of Xinjiang almost universally identify as Moslems, as do millions of their Central Asian Turkic-speaking neighbors. "Cultural identity” as proposed in Fredrik Barth’s (1969) work Ethnic Groups and Boundaries, illustrates the fact that the Uyghurs identification as part of "Moslem culture" is an enormous statement about their role in Chinese society. A recent study of the Uyghurs published by Ildiko Beller-Han (2008) on the period when groups of small communities managed to develop a common identity, 1850-1949, represents a major ethnographic work based on oral history and written records of how this transformation occurred in Xinjiang.

The Uyghur identity emerged from a nomadic and rural group of people with a similar but not identical language which was drawn into modern Chinese society to become a cohesive group with a consciously understood ethnic history. The idea of cultural identity is especially important for Moslem women, because young Moslem women may be one of the most important agents of change in the culture. Cultural identity begins with questions like "Who am I?" "What is most important to me?" "Should I make this choice or another choice in my life's decisions?”

\section{Islamic Practices as a Barrier to Cultural Assimilation}

\subsection{Issues of Cultural Identity}

The important patterns of change that we observe in Uyghur life can be found in cultural identity and the constraints of family control in an evolving urban environment. The important theoretical contributions are those of Valentine Moghamdan for Moslem society, and Linda Benson and Xiaowei Zhang for the Uyghurs. These demonstrate that the choices of Uyghur women can guide the discussion of Moslem women. On one pole is the conservative protection provided by the large patriarchal family that is documented by Dhamiand Sheikh (2000), Xiaowei Zhang (2010), and Benson (2004). The other side of the pole is the modern urban Moslem woman represented in Moghamdan (1993). 
Cultural identity can form a barrier to national assimilation; in a simple example, the consumption of food, M. Cristina Cesaro $(2000,238)$ points out that a common everyday practice such as eating creates group boundaries. The issue of Halal food (food that meets Moslem dietary restrictions) means that Uyghurs cannot easily eat with Han people, who do not have this restriction. Thus, a common everyday practice such as eating creates group boundaries, which help unify the Uyghurs, but separate the Uyghurs from other Chinese.

In addition to the consumption of food, many other features of Uyghur identity serve to isolate them from the larger Chinese society. Uyghur dress is a point of contention; women's use of headscarves has been an issue for Moslem women in China as it has in Western Europe.

There are language differences between Uyghurs and Chinese. In the Xinjiang region, there is often residential separation. Cities in Xinjiang often have two different residential districts, Uyghur and Chinese. Family environment is different as well. Uyghur family life is often based on a large family. Uyghurs are exempt from the Han Chinese's one child policy, which up until now limits the family size of the Han Chinese population.

\subsection{Young Uyghur Moslem Girls and Educational Barriers}

Another concern of Uyghur society, especially with regard to women, has been with educational attainment of girls relative to boys. The historical circumstances that brought the Xinjiang Uyghur Autonomous Region into the New China in 1949 had major consequences for the Uyghur minority. Two school systems were introduced, one in Chinese and the other in Uyghur. Linda Benson observes (2004, 91), "Available Chinese statistics on education (in Xinjiang) give rise to a number of questions... The statistics do not explain why, for example, the percentage of students (Uyghurs) continuing on to middle school remains relatively low. One factor may be the early withdrawal of girls from elementary school." Government figures from the 1990s have shown that young Uyghur girls often end their education with primary school.

Also, from Linda Benson (2004, 199):

The government's undeniable successes (in raising the education level of minorities) are tempered by ongoing problems, some of which trace directly to the continued existence of two separate school systems — one for the minorities taught in their own languages and one offering instruction only in Chinese... Uyghurs and other Muslim peoples link their concern to preserve their culture and identity with the language of instruction in the schools. (Linda Benson 2004, 199)

Uyghur schools may not effectively prepare children for assimilation into Chinese culture, but without these schools, Uyghur culture itself may disappear. Chinese, however, is taught in all Uyghur language schools.

In the establishment of the New China in 1949, the remoteness of Xinjiang and the uncertainties of the new government facilitated the development of two separate school systems. This met the demands of the local population, but it created another obstacle for women. Since families often considered young girls to be "regional;" that is, their future would take place in Xinjiang and in the local Uyghur community, it was often not deemed important for them to gain educational credentials that would qualify them for employment or a vocation in the national community of China. This in turn, means that women do not need to be educated much further than literacy, and their education takes place in Uyghur language schools.

\subsection{Uyghur Moslem Girls and Family Control}

To protect their daughters, Moslem families encouraged them to curtail their education and to marry partners chosen by their parents. Uyghur culture, which is Central Asian culture, has a long history of arranged 
marriage that continues up until the present time. Current research shows that young Uyghur men are given more freedom to choose their brides while Uyghur girls are offered little choice. Dr. Xiaowei Zang (2010) using a data set $(n=1,583)$ collected in the city of Urumchi in 2005 examined Uyghur-Han differences in arranged marriages in Urumchi. Data analysis showed a rapid decline in parental arrangement for both Uyghur Muslims and Han Chinese in Urumchi over the most recent decade. It also showed that Han Chinese are less likely than Uyghur Muslims to report arranged marriages. However, the differences between Uyghur men and Han men fade away when background characteristics are controlled, whereas no similar patterns are found among women. These findings indicate that Uyghur women have a lower degree of autonomy in the marriage market than their Muslim brothers. Comments made by participants in this study illustrate that controlling parents present obstacles to their daughters, such as the reluctance to allow their daughters to go to college outside their regional area, or even to college at all.

\subsection{Turkic and Moslem Traditions and the Freedoms in Beijing}

Students say that it is difficult for young people to investigate their ethnic culture and history in their home city in Xinjiang. Uyghur history and literature is taught in the Uyghur language public schools, but the young women reported that there were more opportunities for investigation in Beijing. Scholars writing on social policy in Xinjiang have agreed with this (Millward and Tursun 2004).

\section{Presenting Three Young Women}

\subsection{Aynur-Uyghur Identity and Career}

The young women who were interviewed are from large rural families. Aynur is a 22-year-old woman from a rural area of Kashgar. Kashgar itself is a large Western urban area with a population of 350,000 residents, over 90\% Uyghur by the 2007 census. The town in which she was raised is rural, with mostly small homes lacking indoor plumbing. Her family and neighbors are farmers. Until a few decades ago there was little motorized travel or rail traffic to the city. Now Kashgar is a major city in the region, with trade ties to Pakistan and Kazakhstan, and an airport. Aynur has two younger sisters and one younger brother.

As a young child, from 1990 to 1996, Aynur lived with her grandparents, her mother having left home for work after a divorce from her father. Her grandfather had a minor government position. Her grandparents lived in a society in which people were barely literate, and her grandfather could hardly read a document before he got his job. Her grandparents were no better educated than their neighbor, although most of the neighbors were farmers and her grandfather was a civil servant. Aynur's grandmother had been a teacher. The couple had six children. "One of my uncles liked reading; he lived in town and every Friday he came back and brought some books and told me about these books and read to me”. Aynur's uncle was a factory worker. When she was old enough, Aynur went to primary school and read by herself. Her aunt taught her how to dance and sing. Aynur "was a smart girl so they had no complaints about my studies in school”.

\subsection{Aynur: Education and Career}

Aynur went to Uyghur schools because there were no Chinese schools in her area at that time. In 1949, at the time of the revolution, Xinjiang had been a region in which most local residents did not speak Chinese, so there was no textbook for the local population other than those in the Uyghur language. A dual school system, one teaching basic subjects in Uyghur and the other teaching basic subjects in Chinese was established. The Uyghurs 
attended Uyghur language schools, and Aynur's education was in these Uyghur schools. This dual education system exists at the current time, but Uyghurs now have a choice of which school they wish to attend.

In the Uyghur school system, Aynur was considered very smart in the class and so the teachers favored her. "They expressed their love without any hesitation. Two teachers in high school showed me the good way to study and plan my life, and I believed them. I would not have (been able to) come to Beijing to study without their help. I believe that education can change a person. Good teachers can help students, and I want to help some students who need help.”

\subsection{Aynur: The Challenge of the Gaokao-The High School Graduation Exam}

If there is one institution that is the source of wide debate in modern China, it is the gaokao. This exam is not required for students who simply want a high school diploma, but each year the teen-age children who are planning to attend college in China take this national competitive exam. It relies heavily on memorized information and it continues for three days.

The challenge of the gaokao is especially difficult in Xinjiang. Most of the Uyghur families in this study chose to send their children to Uyghur language schools. Uyghur language primary and secondary education is widespread in the province, but if parents choose to send their children to these schools, then the children take the gaokao in Chinese as a Second Language, which requires a lesser knowledge of Chinese than that of a regular Chinese high school graduate. Those who take this exam have a limited choice of majors in college. If the students take the gaokao of a regular Chinese high school student, they will take the exam in their second language and competing against Chinese students who are taking the exam in their first language. Despite this, Uyghur parents believe if they do not send their children to Uyghur language schools, then Uyghur language and culture will be lost forever.

Aynur's gaokao was in Chinese as a Second Language, which meant that her college choices and her choices of major were limited. "I give thanks for gaokao, although I hated it. The gaokao changed my life. When I was a high school student I never thought about my future and college. I was scared of taking the gaokao. If you can't do well, you need to wait for one year and take it again. Without passing it, you have no chance to further your education.”

The Chinese as a Second Language in gaokao is comprised of four parts: Chinese, Uyghur literature and language, mathematics, and a fourth comprehensive exam including history, politics, geography, physics, chemistry, and biology.

Aynur's score was one of the highest in her school so she had more choices of universities than her classmates. She chose the Minorities University of China (MUC), where she could get a full scholarship if she majored in Uyghur Language and Literature. Only two people in her school came to Beijing to go to college.

\subsection{Aynur: Career}

Aynur states that:

Maybe for some people, nation is not important as career. But for me and my (Uyghur) friends, we must think about this. In Beijing, we have good opportunity but for girls it is hard to find a Uyghur boy and raise a family. As a Uyghur girl, the family is very important for us. If I go back to Kashgar, perhaps I cannot advance in my career because my family has no connections. Kashgar does not have a large job market like Beijing, so I may not have any chance to prove my abilities for my career. (Aynur 2011) 
What she means by this is that in Xinjiang it is difficult to find a good job if your family cannot help. This "help” represents family connections and influence and in China it is spoken of as guanxi. In her view, Aynur's larger job market in Beijing lessens the need for guanxi.

Beijing had been a dream to her, and this was something that her parents could not refuse. The choices between career and Xinjiang and choosing a major were very problematic for this young woman. Although her parents had been teachers, she is not fond of teaching. She feels that the curriculum in schools is too rigid and the job is too difficult. In addition to the regular curriculum, the students must attend extra Chinese society education classes that take up a great deal of the free time of students and the teachers. Aynur does not feel comfortable engaging in this work.

Instead, what she wants to do is to open up her own educational institution, perhaps a library, and a place where she might have the freedom to educate young Uyghur children with her own curriculum. These are the plans of a young 22-year-old Uyghur woman. They may be difficult to realize, but they represent the attempt of a young woman to balance the strains of parents, opportunities, and the desire for personal independence.

\subsection{Meryam: The Opportunity to Investigate Cultural Heritage}

The most dramatic example of a Uyghur woman exercising the ability to investigate the past is Meryam, a young woman of Kyrgyz-Uyghur descent who wears full Islamic dress. Unlike most others, she wears not simply a headscarf but an entire outfit of modest clothing. Like other Uyghur women, she majors in Uyghur language and literature. What she wants to do is going to school in Egypt to study Islamic education at a world famous institution, Al-Azhar University in Cairo. Founded during 970-972, it is the chief center of Arabic literature and Islamic learning in the world.

Additionally, she would like to visit Turkey. She has had the opportunity to study Turkish and Turkish culture at MUC. Her destination is the world of the Middle East. She then wants to work in Xinjiang as her life's choice. She believes Urumchi, the capitol and the largest city in the province, is the best place for her to work in Islamic education. She comes from a rural background. Her parents were poor farmers, and her grandparents were farmers as well. She has a sister who lives and studies Uyghur Language and Literature in Lanzhou.

Courses in Uyghur Language and Literature at MUC Beijing and Lanzhou include the Islamic and old Turkish heritage of the Uyghur nation. Some students in the Uyghur language department at MUC choose to study "old Turkish," the Chagatai language, an extinct Turkic language which was once widely spoken throughout Central Asia, including Xinjiang, and remained the shared literary language until the early 20th century. Specialists from Turkey serve as visiting professors in old Turkish. There are excellent sources of old Turkic history and culture, and the literature in English, Chinese, and Uyghur is growing.

\subsection{Radiyeh: Family Control and Women's Choices}

Radiyeh is a young woman from Kashgar who speaks excellent English in addition to being fluent in Uyghur and Chinese. Radiyeh's major is similar to the others, Uyghur Language and Literature, but unlike most of the other students, she wants to live away from Kashgar because her parents are too controlling. She faced great opposition from her parents when she wanted to go to school in Beijing, and it was only the fact that she scored well enough on the gaokao to attend a school as prestigious as MUC that they allowed her to leave Xinjiang and go to Beijing. In Xinjiang, Radiyeh is one of the first generation of women to deal with such 
issues. A university opportunity in the capitol of China was beyond the hopes of most Uyghurs from earlier generations. Radiyeh is also escaping from her family background, since her parents, brothers, and sisters are all farmers.

As Radiyeh says: "(In the old days), the child of a farmer would marry a farmer-now a girl (a Uyghur college student) may be more educated than her boyfriend. In the time of her grandmother (the 1950s), the wife usually stayed at home.”

Things are changing in Kashgar, but not quickly enough for Radiyeh. She would like to find a job in Beijing, but even if she found a job back in Xinjiang, she would be reluctant to live near her parents. Issues such as leaving home, going out with boys, and finding a job are all problems in religiously conservative Uyghur families. The fact that Radiyeh went to Beijing was a great problem for her parents. Radiyeh said that in this respect, Xinjiang is like Afghanistan, which borders on Xinjiang on the West. This underlines how severe the limitations on Moslem women in Xinjiang can be. This issue may exist for women all over Central Asia.

Radiyeh is not necessarily worried about the choice of a job; she expected that she would be a teacher. With a major in Uyghur Language and Literature, this is one logical outcome for an educated Uyghur woman. Radiyeh is also interested in becoming a cultural worker, a journalist, or one who works for a museum. Radiyeh hopes that she can get a better job in Urumchi, far across the province from Kashgar. Her first priority is personal freedom.

One of the things that weigh heaviest on Radiyeh's mind is the tradition of arranged marriage. Speaking about Central Asian family practices, Dami and Sheikh write: "In many senses, marriage is considered the union of two families, and the parents usually arrange the marriage. Although the free consent of both the bride and groom are essential, parental coercion is often strong. Some parents are evidently beginning to understand the marital concerns of their children" (Dhami and Sheikh 2000, 353).

The practice of choosing marriage partners from within the parents' community of friends and business acquaintances, however, continues to be considered important by young and old (Dhami and Sheikh 2000). Choosing a spouse may involve family members other than the immediate families of the couple. The matter is further complicated by the high costs of elaborate weddings and dowry, which means the couple will have to rely on parental financial support in order to marry. This in turn increases their dependency on parents and increases parental control.

Facing issues such as these means that a young Uyghur woman must confront her parents at an early age about her hopes and plans, when she is in her teenage years, or be bound to her parents' choice for the rest of her life. These traditions are changing, but young, ambitious women must decide their fate when very young

\section{Minorities Studies, Affirmative Action, and Social Change}

Although few Uyghurs would admit this, one of the great advantages for women in a secular society, like China, is that the government does not reinforce the family values of Xinjiang. In Xinjiang, many parents might prefer their daughters to stay in the local area and marry young. Because of this, a Uyghur high school teacher in a rural area near Kashgar reported that most of his students were young women. In rural areas, women cannot easily find "suitable jobs" and the young women simply refuse to get married. In more urban areas, the teacher said, young women are getting jobs rather than getting married. The observations made about Uyghur women being withdrawn from school even a decade ago may be breaking down. 
Many institutions that directly affect the Uyghur community are beginning to help young women overcome the barriers they face in career, cultural investigation, and personal freedom. An important essay on Moslem women deals precisely with these issues, Lila Abu-Lughod's Do Muslim Women Really Need Saving? (2002, 784). The question being addressed is how Moslem women exercise their freedom in the context of their own societies. The context of these remarks is Afghanistan, but the same issues-education and marriage are involved.

\subsection{The Uyghur Language and Literature Department at Minzu University}

A major in Uyghur Language and Literature is a general liberal arts major, including language, culture, and sociology in the first language of the student. Most of the undergraduate majors are young women, with young men perhaps preferring business or engineering. Most of those who major in this field of study do not have any life experience outside Xinjiang, except for their years in MUC in Beijing. In order to recruit good Uyghur students, MUC offers scholarships to students that major in Uyghur Language and Literature. On the graduate level, there are excellent jobs available in translation, since with eight million Uyghurs, there is a constant demand to translate documents back and forth from Uyghur to Chinese.

MUC students discussed here believe that the departments play a very positive role integrating them to the university and to modern China. Most of the students have not been outside Xinjiang before and comment on the friendships they have made with other Uyghurs at MUC. One freshman at the university reported that her parents were pleased that she made friends with other Uyghurs. In talking about her major, one student commented about an English class she had taken. In such classes, the professor talked the whole time, while in the Uyghur classes, the entire class participated and it was a more interesting class.

Students also mentioned the friendliness of the Uyghur faculty and staff at the school. Uyghur parties and events featured faculty speakers, and at one graduation party, a leading faculty member congratulated all the participants individually. These events draw not only the students, but also the Uyghur community in Beijing, who bring their young children. Department events are posted on Uyghur web sites, and between the Internet and word of mouth, the Uyghur community in Beijing is well represented at Uyghur events at MUC.

As was shown in the case of Aynur and Maryam, these same departments heighten Moslem and Uyghur awareness and solidarity. The Internet and the school expose students to developments in the global Islamic community. They are exposed to speakers and to ideas that are not available in Xinjiang.

Aynur commented on the Uyghur Studies School:

Our department at MUC is very famous in Xinjiang. In Xinjiang University and Xibei Minzu University (in Lanzhou) and in Xinjiang Normal University there are also Uyghur language and literature departments. Our teachers at MUC are good, they have good personalities and they are supportive. There are chances to go abroad; they help us with employment, and provide information. We can learn everything about minority studies if we want. We are in Beijing. Beijing is our New York. (Aynur 11 May, 2011)

The university itself, the Minorities University of China, and the major, Uyghur Language and Literature, represent affirmative action in China. As Chris Evans-Hearne (2009) says:

The Minzu University of China ... is a major ethnic minority university in China. Located in Beijing, approximately $70 \%$ of the students are non-Han Chinese minorities. The school has been designated as a Project 211 School. This means that the government gives the Minzu Funding: University of China special funding and support for the purpose of modernizing and improving the competitiveness of higher education in China. (Chris Evans-Hearne 2009) 
At the same time, there are those that claim there are more effective ways to improve minority education. Mike Ives: "Now there is growing concern that decades-old programs designed to help minority students are not effective." "The proportion of ethnic minority students studying at Chinese universities has not kept pace with an expansion of the nation's higher education system, particularly at China's top-tier universities,” said Gerard Postiglione, Director of the Wah Ching Center of Research on Education in China at the University of Hong Kong. China's ethnic minority education policy is failing to bridge the growing wealth disparity between coastal areas and its interior border regions, he added, "The Chinese government tends to paint a rosy picture by talking about how literacy is going up, but most people feel that in the market economy, there has been a downturn in benefits for minorities."

Another criticism of the current system of affirmative action appears in a discussion by Rui Yang, Mei Wu (2009, 117-121):

Sautman reports that Han students admitted to Xinjiang universities in 1986 averaged 435 points in science and 440 points in liberal arts; whereas minorities averaged 300 points in science and 245 points in liberal arts. In 1987, Han students from Xinjiang admitted to national key universities averaged 472 points in science and 445 points in liberal arts; minority students averaged 313 and 269 points respectively. There are a lot of debates, and not just among scholars, about why China should perpetuate a system where minorities are poor compared to Han Chinese. (Yang Wu 2009, 117)

It is concurred with Dru Gladney, an anthropologist and expert in China's minority policies at California's Pomona College. "Under the old centralized system, the government used to spend a lot of money on the border areas” (Yang Wu 2009, 118), Gladney added. "But now they're relying on the market economy, and many of these 'nationalities' universities have suffered as a result, because their funding hasn't kept pace” (Yang Wu 2009, 118).

The criticism that Uyghur students do not have access to top tier schools must confront the fact that for most Uyghurs, Chinese is a second language. Uyghurs have an enormous attachment to their province, and most plan their future occupation and family life in terms of Xinjiang. Students from highly ranked Chinese universities have little interest in living in a relatively poor rural area such as Xinjiang, far away from the cultural centers of Beijing and Shanghai.

\section{Conclusion}

The argument against affirmative action programs does not take into account the real benefits for cultural identity. Although not immediately apparent to outsiders, the "push" for cultural change is very present in Xinjiang, especially among women. This change is in an unintended direction, since it introduces young students to membership in a larger world Moslem community.

The Minorities University of China provides the chance to participate in the liberalism of Beijing compared to the perceived limitations in Xinjiang province. Experience in the university provides an opportunity for investigation of one's ethnic culture in a way that is not fully explored in Xinjiang. The opportunity to escape parental control is facilitated in college. Education and employment opportunities are the vehicles for group integration into larger Chinese society.

Ethnically oriented institutions such as the Uyghur Department of Language and Literature, which might appear to further separate young people from the Chinese society, actually help to integrate these students into academic life, and at the same time support investigation into an exciting realm of ideas. The Moslem awakening, a process that is still in its early stages in this century, is advancing through the preferences of 
women. It parallels the cultural pride that Han Chinese feel for Chinese development, and hopefully points the way towards equality in a multicultural China.

In Central Asia, and especially in a secular society such as China, university study may introduce young students to membership in a larger world Moslem community.

For the three young women involved, what makes this possible is the competitive high school exam. Nothing is as important as this for providing the opportunity for self-advancement. The gaokao is actually the only door open to these young women. They come from large families in provincial schools far away from the center of Chinese economic and intellectual life. The parents in all likelihood lack the money and guanxi (connections) to offer significant help. The young women are on their own.

\section{Works Cited}

Abu-Lughod, Lila. “Do Muslim Women Really Need Saving?” American Anthropologist 104.3 (2002): 783-90.

Barth, Frederik. Ethnic Groups and Boundaries: The Social Organization of Cultural Differences. Long Grove, Illinois: Waveland Press, 1969.

Beller-Han, Ildiko. Community Matters in Xinjiang: 1880-1949. Leiden: Brill Turkic Series, 2008.

Benson, Linda. "Education and Social Mobility Among Minority Populations in Xinjiang.” Ed. S. F. Starr. Xinjiang, China's Muslim Borderland. London: M.E. Sharpe, 2004. 190-215.

Cesaro, Christine. "Consuming Identities: Food and Resistance Among the Uyghurs in Contemporary Xinjiang.” Inner Asia 2.2 (2000): 225-38.

Sangeeta Dhami, and Aziz Sheikh. “The Muslim Family: Predicament and Promise.” West Journal of Medicine November 173.5 (2000): 352-56.

Evan-Hume, Christopher. "Minzu University of China”(2009). <http://suite101.com/article/ minzu-university-of-china- a113718>. Ives, Mike. “China: Time to Re-assess Minority Education.” World University News. 19 December 2010. 152.

Makofsky, David. "Cultural Change in the Educational Setting: The Integration of Young Moslem Women Into Chinese Society.” European Journal of Applied Social Sciences Research (EJASSR) 1.2 (2013): 51-57. <www.ejassr.org>.

Millward, James, and Torsun, Norum. "Political History and Strategies of Control.” Ed. S. F. Starr. Xinjiang, China's Muslim Borderland. London: M. E. Sharpe, 2004. 27-63.

Moghamdan, Valentine. Modernizing Women: Gender and Social Change in the Middle East. Boulder Colorado: L. Rinner, 1993. Rui Wang, and Mei Wu. “Education for Ethnic Minorities in China: A Policy Critique.” SA-e DUC Journal 6.2 (2009): 117-31.

Zhang, Xiaowei. "Gender and Uyghur-Han Variation in Arranged Marriages in Urumchi.” China Westminster Forum, Sheffield University, 15 October, 2010. 